\title{
Validity and reliability of hausa version of the oswestry disability index
}

\author{
Olusola Ayanniyi $\mathrm{PhD}^{1}{ }_{\mathrm{ABCDEFG}}$, Anthony Ajayi MSc $\mathrm{PT}^{2}{ }_{\mathrm{ABCDEFG}}$, Chidozie E. Mbada $\mathrm{PhD}^{3}{ }_{\mathrm{ABCDEFG}}$, \\ Mohammed A. Auwa ${ }^{12}$ ABCDEFG \\ ${ }^{1}$ Department of Physiotherapy, College of Medicine, University of Ibadan, Ibadan. Nigeria \\ ${ }^{2}$ Department of Physiotherapy, Ahmadu Bello University Teaching Hospital, Zaria. Nigeria \\ ${ }^{3}$ Department of Medical Rehabilitation, College of Health Sciences, Obafemi Awolowo University, \\ Ile-Ife, Nigeria
}

\begin{abstract}
Background: Translation of psychometrically sound instruments into different local languages is perceived to allow easy accessibility and understanding of the instruments. There is a dearth of valid and reliable versions of the Oswestry Disability Index (ODI) in Nigerian languages. The purpose of this study was to translate and establish the psychometric properties of the Hausa version of the ODI (ODI-H). Materials and Methods: This cross-sectional study recruited 100 (50 males and females respectively) patients with chronic LBP from six purposively selected outpatient physiotherapy departments in the Northern part of Nigeria. The 'translation backward translation' method was used to translate the English version of ODI into the Hausa language. The English version of the ODI, ODI-H and the Visual Analog Scale (VAS) were administered to respondents in this study. The data was analyzed using descriptive and inferential statistics. Alpha level was set at $\mathrm{p}<0.05$.

Results: The mean age of participants was $44.5 \pm 12.8$ years. The mean disability score on the English version of ODI and ODI-H was $16.3 \pm 6.66$ and $17.7 \pm 7.13$ respectively. The mean ODI-H score on 7-days retest was $17.8 \pm 6.87$. The mean VAS score of the respondents was $5.62 \pm 2.00$. The mean time for completion of the ODI-H was 6 minutes. There was significant correlation between VAS score and ODI-H $(r=0.665 ; \mathrm{p}=0.001)$; English and ODI and ODI-H ( $r=0.914 ; \mathrm{p}=0.001)$, and the test-retest of ODI-H $(r=0.969 ; \mathrm{p}=0.001)$ respectively. The Cronbach-alpha and ICC value for the validity and test-retest reliability of the ODI was 0.961 and 0.924 ; and 0.987 and 0.973 respectively.

Conclusion: The Hausa version of the ODI has excellent reliability and validity and may be an appropriate outcome tool for evaluating functional disability among Hausa speaking patients with chronic LBP. Therefore, the ODI-H is an appropriate outcome tool for clinical and research purposes among Hausa speaking patients with LBP.
\end{abstract}

Key words: Oswestry Disability Index, Translation, Reliability, Validity, Hausa, Nigeria

\section{Introduction}

Evaluation of functional disability in patients with Low-Back Pain (LBP) with the use of psychometrically sound instruments or questionnaires are important in identifying appropriate interventions and assessing treatment outcomes [1,2]. Oswestry Disability Index (ODI) is one of the commonly used outcome tools for evaluating functional disability in LBP [3-6]. ODI developed by Fairbank et al [7] is a self-administered questionnaire which assesses the extent of pain and functional limitation in patients with LBP [7-9]. Following its development, the ODI has been employed in many clinical and research settings specifically, the psychometric values of ODI ranges from 7.1 to 8.7 for validity, and 0.83 to 0.99 for reliability [10].
Based on its clinical usability and psychometric properties, the ODI has been translated into more than ten different languages and the different translations were found to be consistent with the original English version in terms of validity and reliability [7-10]. Translation of the ODI into different local languages is perceived to allow easy accessibility and understanding of the questionnaire by patients. Therefore, it has been suggested that one major way of increasing the use of an instrument in any population is to have the instrument translated into local languages spoken in that population [11]. However, there seems to be a paucity of translations of the ODI in Nigeria languages. Hausa language is one of the three major Nigerian languages. As such, Hausa language is the main lingua franca throughout Northern Nigeria, as well 
as in countries Niger, Mali, Chad, Northern Part of Benin republic, Ghana, Cameroon and in some smaller communities scattered throughout West Africa [12]. The objective of this study was to translate and test the validity and reliability of the Hausa version of the ODI (ODI-H).

\section{Materials and methods}

A total of 100 (50 males and females respectively) patients with chronic LBP participated in this study. The patients' were recruited from physiotherapy outpatient departments of six tertiary hospitals covering the three zone (West, Central and East) in the northern part of Nigeria. The hospitals are the Ahmadu Bello University Teaching Hospital, Zaria; National Orthopedic Hospital, Dalla, Kano; Aminu Kano Teaching Hospital, Kano; University of Maiduguri Teaching Hospital, Maiduguri; Usman Danfudo University Teaching Hospital, Sokoto; and University of Jos, Teaching Hospital, Jos.

Inclusion criteria for participation in this study were having non-specific LBP of three months and greater, being 18 years and older, and having no associated co-morbidity such as cancer, diabetes and stroke. Ethical approval for the study was obtained from the Joint ABU/ABUTH Institutional Review Committee before the commencement of the study. Permission to undertake the study was also obtained from the heads of physiotherapy departments of the selected hospitals. Every volunteer for the study gave signed informed consent after full disclosure of the purpose of the study.

\section{Instruments}

\section{Oswestry Disablity Index - English Version}

The ODI assesses level of functional disability in patients with LBP [7]. ODI comprises of ten sections covering pain intensity, personal care, lifting, walking, sitting, standing, sleeping, social life, traveling, and employment and home making. Each item ranges from 0 to 5 and the sum of the 10 scores is expressed as a percentage of the maximum scores, varying from 0 (no disability) to 100 (maximum disability). The questionnaire is completed in about 5 minutes and scored in less than 1 minute [7].

\section{Hausa translation of the Oswestry disability index}

The Hausa translation was obtained using the 'translation backward translation' method [13] in which the original version of the ODI translated by a Hausa language specialist in the department of Hausa language, Ahmadu Bello University Zaria. Copies of the Hausa translation of the instrument were then given to 3 bilingual individuals who are knowledgeable about the content area to translate back to English (back- translation) to ensure that the original meaning is not lost or altered [13]. The corrected Hausa version (ODI-H) was then used to gather information about the degree of functional limitation of participants with LBP.

\section{Visual Analog Scale (VAS)}

Visual Analog Scale was used to assess pain intensity. VAS is a psychometric response scale which can be used to measure a characteristic or attitude that is believed to range across a continuum of values and cannot easily be directly measured [14]. The scale is made of a $10 \mathrm{~cm}$ horizontal line with "no pain" written at one end and "worst pain' ever felt at the other end [15]. VAS is a valid indicator of pain changes with psychometric values of $r=0.67$ to 0.90 for validity and reliability $r=0.99$ [15-18].

\section{Administration of the questionnaire}

1. Socio demographic data on age, sex, occupation, marital status, and data on clinical history of LBP was collected from the respondents. The respondents were assigned numbers as they were recruited into the study.

2. The ODI-H was administered to every odd numbered respondent first and then the English version of the ODI after 30 minutes of completion of the ODI-H. On the other hand, every even numbered respondents received the English version of the ODI first, then the ODI-H.

3. The VAS was administered to the respondents and each respondent was asked to mark a point he/she fills corresponds to the present level of pain. The marked point on the scale was then transferred to a ruler, and was read and recorded.

4. The ODI-H was re-administered to the respondents' 7 -days after the first administration to assess the test-retest reliability of the Hausa translation.

\section{Data Analysis}

Descriptive statistics of mean and standard deviation were used to summarize data. Inferential statistics of Independent t-test was used to compare the ODI scores obtained between the patient and 
their apparently healthy counterparts. Spearman correlation was used to test the correlation between the pain intensity scores on the VAS and ODI versions. Intra-Class Correlation and Cronbach (a)-alpha was used to test for the validity and reliability of the ODI-H. Scattered plot was used to depict the correlation between English version of the ODI and the ODI-H, as well as the test-retest of the ODI-H. Data was analyzed using SPSS version 16.0. Alpha level was set at $\mathrm{p}<0.05$.

\section{Computation}

A score of 0-5 is possible for each of the ten categories on the ODI where 0 to 5 correspond to A-F for each category respectively, which provides a total possible score of 50 if all responses were 5 . This score was then doubled to define the answer on a $100 \%$ scale where 100 represent the highest disability score possible. The percentage disability was calculated as -

Score obtained $* 100 /$ Number of section completed ${ }^{\star} 5$ [7].

The scores where then interpreted as -

0-20\% Minimal Disability

20-40\% Moderate Disability

40- 60\% Severe Disability

$60-80 \%$ very severe Disability

$80-100 \%$ the patients are either bed bound or exaggerate the symptoms [7].

\section{Results}

The mean age of participants was $44.5 \pm 12.78$ years. The respondents were comparable in age by gender $(46.9 \pm 13.2$ years (male) vs. $42.4 \pm 12.0$ years (female); $\mathrm{t}=1.807 ; \mathrm{p}=0.074)$. The summary of respondents' scores on ODI and VAS is presented in table 1 . The mean disability score on the English version of ODI and ODI-H was $16.3 \pm 6.66$ and $17.7 \pm 7.13$ respectively. The mean score ODI-H score on 7 -days retest was $17.8 \pm 6.87$. The percentage disability index of the respondents using English ODI, ODI-H and on ODI-H retest was $32.6 \%, 35.5 \%$, and $35.6 \%$ respectively. The mean VAS score of the respondents was $5.62 \pm 2.00$ (table 1). The mean time for completion of the ODI-H was 6 minutes.

There was significant correlation between VAS score and ODI-H ( $\mathrm{r}=0.665 ; \mathrm{p}=0.001)$; English and ODI and ODI-H $(r=0.914 ; p=0.001)$, and the test -retest of ODI-H $(r=0.969 ; p=0.001)$ respectively. The Cronbach ( $\alpha$ ) alpha and ICC value for the validity of the ODI-H was 0.961 and 0.924 respectively. The lower and upper limit 95\% Confidence Interval (CI) for the ICC value of the ODI-H va- lidity was 0.890 and 0.949 respectively. Also, the $\alpha$-alpha and ICC value for the test-retest reliability of the ODI on 7-days interval was 0.987 and 0.973 respectively. The lower and upper limit 95\% Confidence Interval (CI) for the ICC value of the ODI $-\mathrm{H}$ validity was 0.961 and 0.982 respectively. The scattered plot showing the correlation between the English ODI and ODI-H, and ODI-H on test-retest is shown in figures 1 and 2 respectively.

\section{Discussion}

This study was aimed to translate and test the validity and reliability of the Hausa version of the ODI (ODI-H). The Hausa people constitute the largest population in West Africa of over 60 million people [19]. Historically, the present day Hausa people in Nigeria hail from the Hausa Bakwai, and are mainly from the seven ancient states of Biram, Daura, Gobir, Kano, Kastina, Rano and Zaria [12]. In a bid to develop a psychometrically sound translation of the ODI in Hausa, native Hausa speakers who were patients with chronic LBP were recruited. The respondents were within the ages of 35 and 55.4 years bracket, in which LBP is predicted to be prevalent [20]. Although, LBP can occur in any age, however, persons of age 40 years and older are reported to be more frequently affected $[21,22]$. Furthermore, the patients in this study had moderate pain intensity level as at the time of the study. The mean score on the English, first and second administration of the Hausa version of the ODI were $16.32,17.74$ and 17.82 respectively. This translates to a disability index of $32.64 \%, 35.48 \%$ and $35.64 \%$, indicating that most participants were moderately disabled.

The result of this study shows a moderate $(\mathrm{r}=$ $0.665)$ criterion validity on the correlation between pain intensity and ODI-H. Previous translations of the ODI in Turkish [23], Korean [5] and German [24] languages found criterion validity for ODI in correlation with pain intensity to range from $\mathrm{r}=$ 0.37 to 0.780 . It is implied that the ODI-H has moderate ability to detect pain in patients with chronic LBP using the VAS as a gold standard.

The ODI-H has high construct validity when correlated with the English ODI $(r=0.914)$.

The magnitude of correlation obtained for the construct validity of the ODI-H is similar to findings of Kim et al [5], Yakut [23] and Fujiwara et al [4] who reported correlation co-efficient values of $0.86,0.833$, and 0.93 respectively. The $\alpha$-alpha (0.961) and ICC (0.924) value for the construct validity of the ODI-H was very high. It is adduced 
that the ODI-H is strongly correlated with English ODI, and that the content validity has not been lost to translation.

The test-retest reliability of the ODI-H, based on the Spearman's co-efficient $(\mathrm{r}=0.969)$, internal consistency (0.987) and ICC (0.973) results was high. Based on Spearman's co-efficient, the finding of this study is in agreement with the results obtained by Boscaincos et al [3] and Fujiwara et al [4]. Even though, correlation coefficients are helpful to elucidate the extent to which two repeated measures can be fitted by a straight line, however, it has significant shortcomings, in that it correlates overall outcomes rather than pairwise repeated measures, which may vary statistically. Use of ICC along correlation co-efficient in reliability test is acceptable as it assesses magnitude of correlation, as well as the degree of relationship and variance between each paired repeated measures. Therefore, the comparable findings on test-retest reliability based on the outcome of Spearman's co-efficient, $a$-alpha (for internal consistency test) and ICC indicate that the ODI-H is very reliable both on item-by-item pairwise comparison and on overall correlation.

In sum, the validity and reliability of the translation of the ODI for evaluating functional disability among Hausa speaking patients with chronic LBP is very high. The construct and criterion validity of the ODI-H is comparable with the original English and other translated versions. To our knowledge, this is the first study to translate the ODI, and also establish psychometric properties for the Hausa speaking population. Potential limitation of this study includes the inability to randomly recruit patients into the study. Also, all the patients in this study were those who were receiving physiotherapy as at the time of the study. It is plausible that the conduct of this study among respondents of a different orientation or other patients groups may yield different outcome. It is therefore, recommended that the external validity of the ODI-H among other patients groups with pain and disability be verified.

\section{Conclusion}

The Hausa version of the ODI has excellent reliability and validity and may be an appropriate outcome tool for evaluating functional disability among Hausa speaking patients with chronic LBP. Therefore, the ODI-H is an appropriate outcome tool for clinical and research purposes among Hausa speaking patients with LBP.
Table 1: Summary Statistics of respondents' scores

\begin{tabular}{|l|l|l|l|l|l|l|}
\hline & $\begin{array}{c}\text { Male } \\
(\mathrm{n}=50)\end{array}$ & $\begin{array}{l}\text { Female } \\
(\mathrm{n}=50)\end{array}$ & \multicolumn{2}{|l|}{} & \multicolumn{2}{|c|}{$\begin{array}{l}\text { All respondents } \\
(\mathrm{N}=100)\end{array}$} \\
\hline Variable & $\mathrm{X} \pm \mathrm{SD}$ & $\mathrm{X} \pm \mathrm{SD}$ & $\mathrm{t}$-cal & $\begin{array}{l}\text { p-va- } \\
\text { lue }\end{array}$ & $\mathrm{X} \pm \mathrm{SD}$ & $\begin{array}{l}\% \\
\text { disa- } \\
\text { bility }\end{array}$ \\
\hline $\begin{array}{l}\text { English } \\
\text { ODI }\end{array}$ & $15.1 \pm 5.93$ & $17.6 \pm 7.10$ & -1.925 & 0.057 & $16.3 \pm 6.66$ & 32.6 \\
\hline $\begin{array}{l}\text { Scores on } \\
\text { ODI-H }\end{array}$ & $16.3 \pm 6.55$ & $19.2 \pm 7.44$ & -2.082 & 0.040 & $17.7 \pm 7.13$ & 35.5 \\
\hline $\begin{array}{l}\text { Scores on } \\
\text { ODI-H } \\
\text { (retest) }\end{array}$ & $16.6 \pm 6.13$ & $19.1 \pm 7.38$ & -1.827 & 0.071 & $17.8 \pm 6.87$ & 35.6 \\
\hline $\begin{array}{l}\text { Pain } \\
\text { scores on } \\
\text { VAS }\end{array}$ & $5.39 \pm 2.09$ & $5.77 \pm 1.96$ & -0.946 & 0.346 & $5.62 \pm 2.00$ & \\
\hline
\end{tabular}

Key: ODI - Oswestry Disability Index, LBP-Low-Back Pain, VAS -Visual Analog Scale

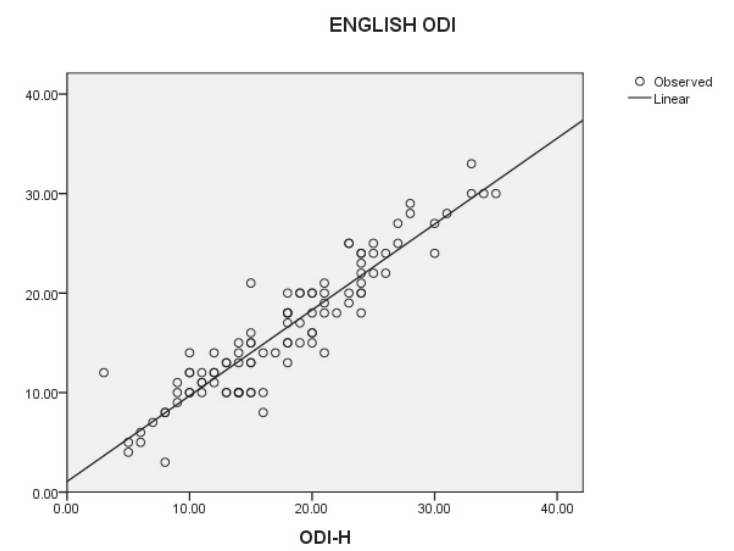

Figure 1: Scattered plot on correlation between English ODI and ODI-H

ODI-H

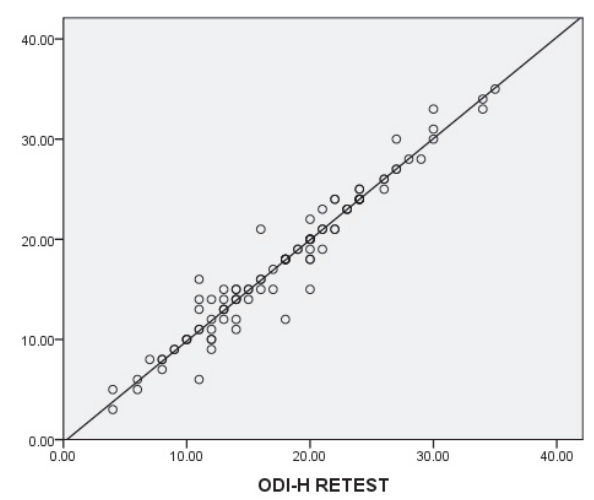

$\circ$ Observed
Linear

Figure 2: Scattered plot on correlation between ODI-H on test and retest 


\section{References:}

1. Delitto A, Erhard RE, Bowling RW. A treatment-based classification approach to low back syndrome: identifying and staging patients for conservative treatment. Phys Ther. 1995;75:470-485.

2. Fritz JM, Cleland JA, Childs JD. Subgrouping patients with low back pain: evolution of a classification approach to physical therapy. J Orthop Sports Phys Ther. 2007;37(6):290-302.

3. Boscainos P, Sapkas G, Stillanessi E. Greek versions of the Oswestry Disability Index and Roland Morris Disability questionnaire. Clinical Orthopaedic. 2003; 41:40-53.

4. Fujiwara A, Kobayashi N, Saiki K. Association of Japanese Orthopaedic Association score with the Oswestry Disability index, Roland Morris Disability Questionnaire and Short-Form 36. Spine. 2003;28: 1601-1607.

5. Kim D, Lee S, Lee H. Validtion of the korean version of the Oswestry Disability Index. Spine. 2005; 30:123-127

6. Maughan EF and Lewis JS. Outcome measures in chronic low back pain. Eur Spine J. 2010: 19:1484-1494.

7. Fairbanks JCT, Couper J, Davies JB and O'Brien JP. The Oswestry Back Pain Questionnaire. Physiotherapy. 1980; 66: $271-273$.

8. Baker DJ, Pynsent PB, Fairbank JC, Roland MO, Jenner JR, editors. In: Back pain: New approaches to rehabilitation and education Manchester. Manchester University Press; 1989. p. 174.-186.

9. Fairbank JC, Pynsent PB. The oswestry Disability Index. Spine. 2000; 25(22): 2940-52.

10. Michael V. Psychometric properties and clinical usefulness of Oswestry Disability Index. Journal Chiropractic Medicine. 2008; 7(4):161-163.

11. McDowell I and Newell C. Measuring Health. A guide to rating scales and Questionnaires second edition. Oxford University Press. New York pg. 1-400. 1996.

12. Odiaka S. Teach yourself Hausa language. 2006. www. Hausalanguage.com Accessed on 20/03/2016

13. Streiner LD and Norman RG. Health measurement scales; A Practical guide to the Development and use (first edition). University Press Oxford New York. 1991.

14. Gould D. Visual analog scale. Journal of Clinical Nursing. 2001. 10:697-706.

15. Price DD, McGrath PA, Raffi A, Buckingham B. The validation of visual analogue Scales as a Ratio scale measures for chronic and experimental pain. Pain. 1983; 17: 45-46.

16. Akinpelu $\mathrm{AO}$ and Olowe OO. Correlative study of 3 pain rating scales among Obstetric patients. African Journal of Medicine and Medical Science. 2002; 31: 123- 126.

17. Jensen MP and Karoly P. Self-report scales and procedures for assessing pain in adults. In: Turk DC,
Melzark R. eds. Handbook of pain Assessment. New York, NY: Guilford Press. 1993.

18. Soyanwo OA, Amanor-Boadu SD, Sanya AO, Gureje O. Pain Assessment in Nigerian Visual Ana$\log$ Scale and Verbal Rating Scale compared. West African Journal of Medicine. 2002: 19:242-245

19. www.Hausa.net (2006): Hausa people (2006): History of the Hausa people. . www.Hausa.net. Accessed on $10 / 02 / 2016$

20. Andersson GBJ. The Epidemiology of Spinal Disorders. In Frymoyer JW (ed.) The Adult Spine: Principles and Practice. Philadelphia, Lippincott-Raven, 1997, pp. 93-141.

21. Borenstein DG. Epidemiology, Etiology, Diagnostic evaluation and Treatment of Low-Back Pain. Current Opinion in Rheumatology. 1999; 11(2):151-157.

22. Waddell G. The Back Pain Revolution. Lincoln (United Kingdom): Churchill Livingstone. 1998

23. Yakut E, Duger T, Oksuz C. Validation of the turkish version of the Oswestry Disability Index for patients with LBP. Spine. 2004; 29:581-585

24. Mannion A, Junge A, Fairbank J. Development of German version of oswestry disability index part 1; cross cultual adaptation, reliability and validity. European Spine Journal. 2005; 15: 55-65.

\section{Acknowledgement}

Special thanks goes to Mallam Abubakar Sarki Mohammed of the Department of Hausa Language, Ahmadu Bello University, Zaria for his technical input in the translation process of the ODI-H. Worthy of acknowledgment are the Heads of the selected physiotherapy department for graciously giving administrative approval to include their facilities in this study. We thank Miss. Bunmi Oguntoyinbo for the secretarial assistance.

\author{
Corresponding author adress: \\ Dr Olusola Ayanniyi PhD PT; FMII \\ Department of Physiotherapy \\ College of Medicine \\ University of Ibadan, Ibadan. Nigeria.
}

